江上 泰広 (日本学術振興会·科学技術特別研究員)， 飯島 由美，浅井 圭介○(航空宇宙技術研究所)

\title{
Low-Speed PSP Experiment using an Automobile Model
} EGAMI Yasuhiro, IIJIMA Yoshimi, and ASAI Keisuke.

\begin{abstract}
We have applied PSP to low-speed wind tunnel tests of an automobile model. PSP measurements at low speeds are difficult because of small changes of pressure on a model. To evaluate the accuracy of current PSP system, we made low-speed PSP experiments using an automobile model in the range of $10 \cdot 50 \mathrm{~m} / \mathrm{s}(36 \cdot 180 \mathrm{~km} / \mathrm{h})$. Effects of averaging, image registration, flat-field correction and calibration were investigated. It was found that, using an in situ calibration, quantitative pressure distributions of the automobile model could be obtained down to $25 \mathrm{~m} / \mathrm{s}$. A comparison of the PSP data with conventional pressure tap measurements revealed that the largest source of an error was derived from the temperature dependence of PSP.
\end{abstract}

Keywords: Pressure-Sensitive Paint (PSP), Low speed, Automobile

\section{1. 緒 論}

圧力孔を用いた圧力計測に代わる方法として高空間 解像度の圧力の面計測を可能にする感圧塗料（PSP）を 用いた計測技術が盛んに研究されている1，2．PSPはこ れまで主に航空機などの高速流体の試験に用いられ大き な成果をあげてきている。一方，PSPを低速に扔ける圧 力計測に適用する試みもなされてきている3) 7).しかし 低速では圧力変動が微小だという問題がある。風速 $50 \mathrm{~m} / \mathrm{s}(180 \mathrm{~km} / \mathrm{h})$ と $10 \mathrm{~m} / \mathrm{s}(36 \mathrm{~km} / \mathrm{h})$ では動圧はそれぞれ

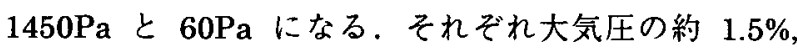
0.06\%に相当する．PSP は原理的に絶対圧センサである ため，この微少な圧力変動を精度よく測定することは非 常に困難である.

本研究では自動車模型を用いた風速 $50 \mathrm{~m} / \mathrm{s}$ 以下の領域 に扔けるPSP 圧力計測を試みた。そしてその測定精度, 誤差要因に関する議論を行う。

\section{2. 低速 PSP 試験の概要}

\section{1 感圧塗料}

本実験では，感圧色素には Pt meso-Tetra(Pentraflurophenyl)-Porphine (PtTFPP), バインダーにはフッ 素系ポリマーの poly(IBM-co-TFEM)を用いた。感圧塗 料は圧力だけでなく温度変化によっても発光強度が変化 し, 圧力測定の誤差の大きな原因となっている。フッ素 系ポリマーを用いた感圧塗料は従来のシリコンポリマー (GP197 など)を用いたものと比較して温度感度が非常に 小さく，高精度の測定を可能とする ${ }^{8)}$ ，自動車模型には 白下地を塗布した上にエアブラシを用いて感圧塗料を塗 布した。

\section{2 自動車模型}

Fig. 1 に本試験で用いた自動車模型を示す．模型は全 長 $221 \mathrm{~mm}$, 高さ $96 \mathrm{~mm}$, 幅 $90 \mathrm{~mm}$ のハッチバックタイ プであり，直径 $7 \mathrm{~mm}$, 長さ $10 \mathrm{~mm}$ の円柱状のサイドミラ 一を有する，材質はアルミ合金であり，模型は中空にな っている. PSP データと比較するために模型上面の流れ 方向のセンターラインに沿って直径 $0.5 \mathrm{~mm}$ の圧力孔が 16 点設けられている. 区別のためボンネット，フロント ガラス，屋根，リアガラスの各部をそれぞれ Part1〜4 と名づける。

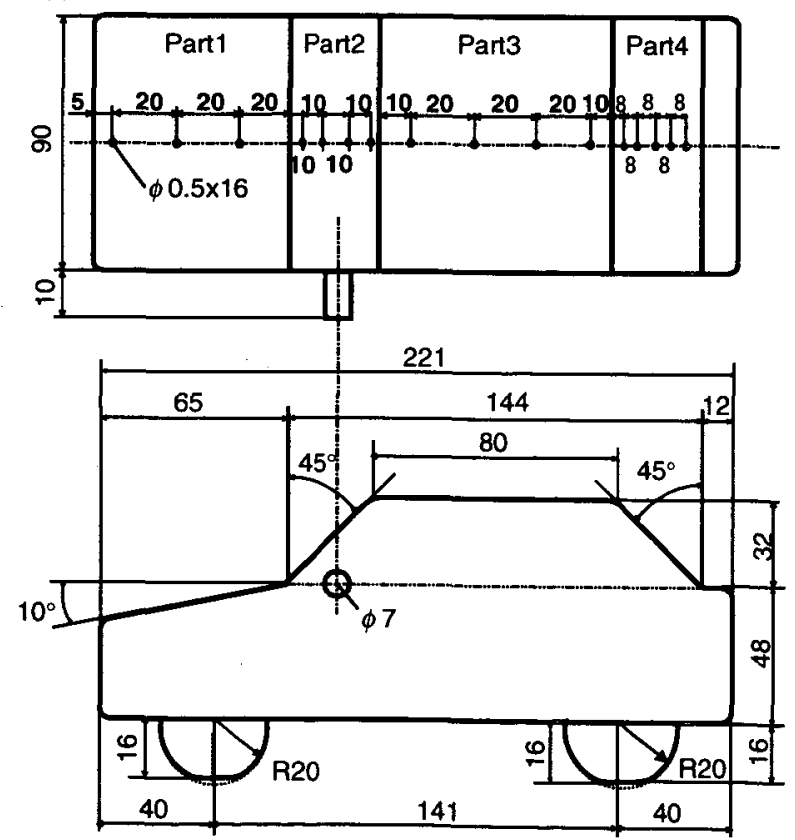

Fig. 1 Schematic of an automobile model 


\section{3 計測系}

Fig. 2, 3 に本試験で用いた光学系の概略と写真を示す. 風洞側壁はアクリル板で作られておりこここを通じて測 定及び観察を行った。感圧塗料の蛍光物質の励起にはキ セノンランプを用い照射ヘッドには 380-530nm のバン ドパスフィルタと $800 \mathrm{~nm}$ 以上の赤外を遮断する熱戦吸 収フィルタを設置した。発光強度の測定には浜松ホトニ クス製の高感度 CCD カメラ（解像度 14bit,有効画素数 $1000 \times 1018$ ピクセル）を用いた。撮影はゲイン Low で 行った。カメラレンズには $650 \pm 20 \mathrm{~nm}$ の干渉フィル夕 を取り付けた. CCD カメラの露光時間は照射へッドに取 り付けられたメカニカルシャッターによって制御した。 得られた画像はパーソナルコンピューターに取り込み, ハードディスクに記録した。

\section{4 風洞装置}

低速 PSP 試験は，航技研小型低乱風洞で行った。この 風洞は回流連続式風洞で幅 $550 \mathrm{~mm} \times$ 高さ $650 \mathrm{~mm}$ の測定 部を持つ、下面壁から $100 \mathrm{~mm}$ の高さに長さ $550 \mathrm{~mm}$, 幅

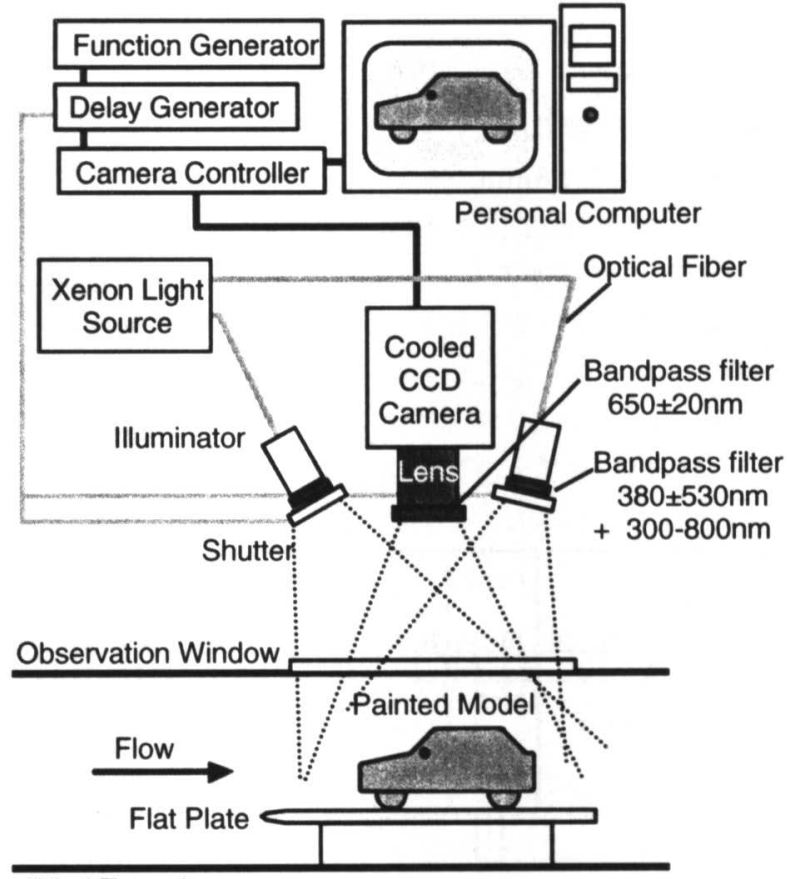

Wind Tunnel

Fig. 2 Schematic diagram of optical setup.

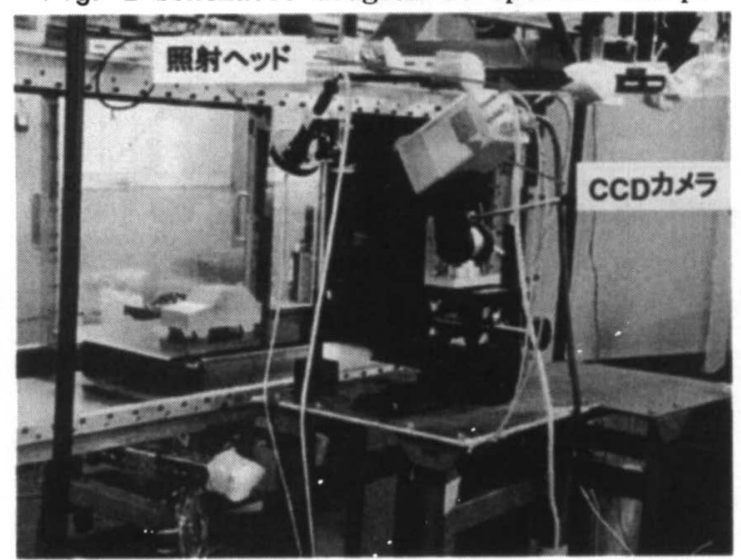

Fig. 3 Picture of experimental setup.
$400 \mathrm{~mm}$, 厚さ $10 \mathrm{~mm}$ の地面板を設け，その上面中央自動 車模型を設置した. 試験条件とその動圧を Table 1 に示す。 試験は主流速度 $50,25,10 \mathrm{~m} / \mathrm{s}$ の三条件で行った，風洞の 温度変化による測定誤差を最小にするために, 各条件で 1 時間以上予備通風を行い装置全体の均温化を図った。

Table 1 Experimental conditions

\begin{tabular}{|cc|c|}
\hline \multicolumn{2}{|c|}{ Mean Velocity } & Dynamic Pressure \\
\hline $50 \mathrm{~m} / \mathrm{s}$ & $(180 \mathrm{~km} / \mathrm{h})$ & $1450 \mathrm{~Pa}$ \\
\hline $25 \mathrm{~m} / \mathrm{s}$ & $(90 \mathrm{~km} / \mathrm{h})$ & $370 \mathrm{~Pa}$ \\
\hline $10 \mathrm{~m} / \mathrm{s}$ & $(36 \mathrm{~km} / \mathrm{h})$ & $60 \mathrm{~Pa}$ \\
\hline
\end{tabular}

\section{5 画像の取得とその処理}

予備通風を行った後,まず 64 枚連続で通風時画像を取 得した.その後直ちに風洞を停止し無風時画像を 64 枚取 得した. 64 枚取得するのに約 30 分要する. 通風時と無 風時の温度差を最小にするため, 画像の平均は通風と停 止した時点を基準点とし, 通風画像は遡って, 無風画像 は取得順に一定枚数平均した。この結果より画像の平均 化の効果を評価した。画像は平均化する前に各画像に位 置補正を行った. 今回の実験では, 主流速度が小さいこ ともあり模型位置の変化は大きくはない.また, CCD 素 子とレンズの特性を考慮に入れるためにフラットフィー ルドを撮影したデータで各画像を補正した。

\section{3. 実験結果}

\subsection{In-situ 較正}

Fig. 4 に各測定条件における in situ 較正曲線を示す。 in situ 較正とは発光強度比と圧力孔デー夕を比較する較 正方法である。ここでは通風／無風画像をそれぞれ 4 枚 平均した場合の結果を示している。これを見ると主流速 度の大きい $U=50 \mathrm{~m} / \mathrm{s}$ のケースは一本の較正曲線によく載 っているのに対し, $U=25,10 \mathrm{~m} / \mathrm{s}$ と速度を小さくしていく とデータのばらつきが大きくなった，特にリアウインド ウの部分（part4）では大きな差異が見られた。この理由 に関しては後ほど議論するが, 較正曲線を求める際にこ の部分のデータは除外した。圧力変動幅はそれぞれ主流 の(a)約 $2 \%$, , b) $0.6 \%$, (c) $0.1 \%$ に相当する. 較正曲線の標準 偏差は各圧力変動幅の約 $4 \%, 7.5 \%, 16 \%$ あった.
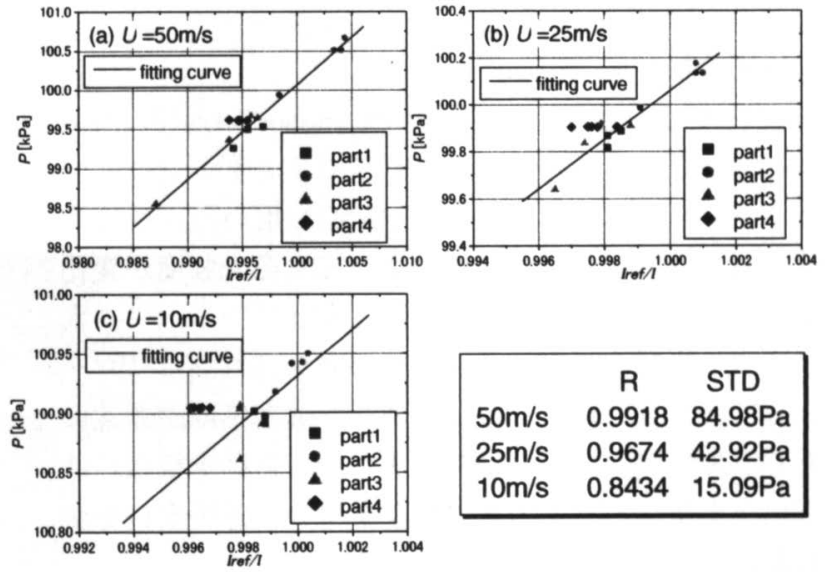

Fig. 4 In-situ calibrations for each test condition. 
Fig. 5 はPSP によって得られた自動車模型上の圧力分布 を示している.画像の数字は「通風画像一無風画像」の 平均した枚数をそれぞれ示している。ノイズの大きさを 純粋に評価するためフィルタリングなどの処理は行って いない. 各画像ともフロントガラスで圧力が上昇し, 屋 根の部分で一度流れがはく離し圧力が低下し，その後再 付着に伴い圧力が回復する様子が良く捉えられている。 またフロントガラスの両端の部分ではく離している様子 も観察された。 カメラのショットノイズに由来するノイ ズは画像の平均枚数を増すにしたがって隇少しているこ とがわかる。また，主流速度が小さくなり圧力変動が小 さくなると, ショットノイズの成分も大きくなることが わかる. 模型側面の圧力が高く示されている部分は励起 光フィル夕から漏れた赤外線に影響されたと思われる誤

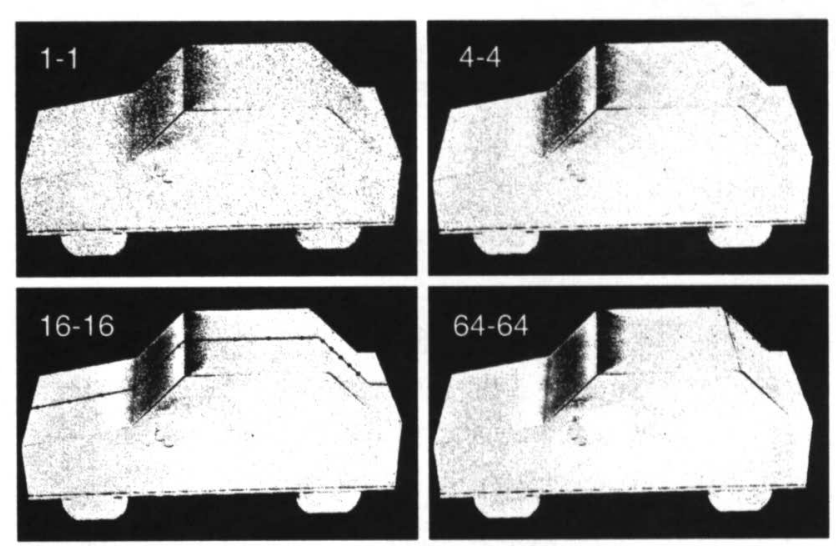

(a) $U=50 \mathrm{~m} / \mathrm{s}$
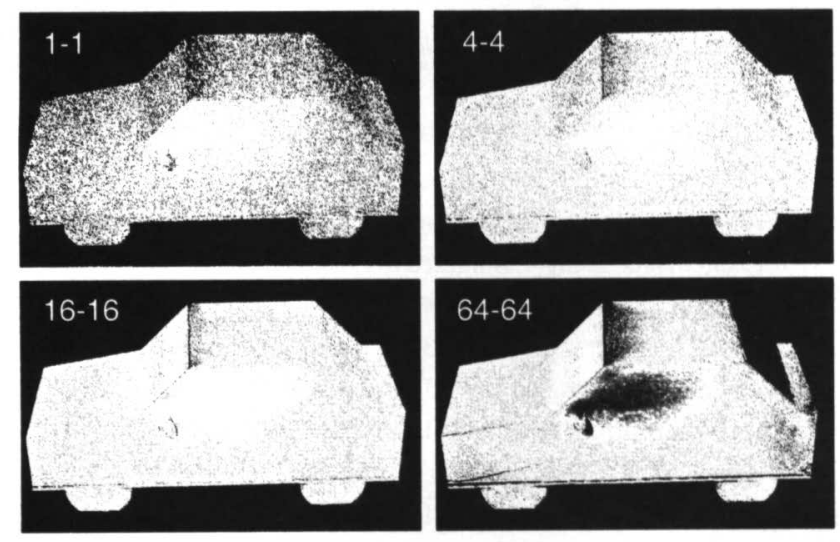

(b) $U=25 \mathrm{~m} / \mathrm{s}$
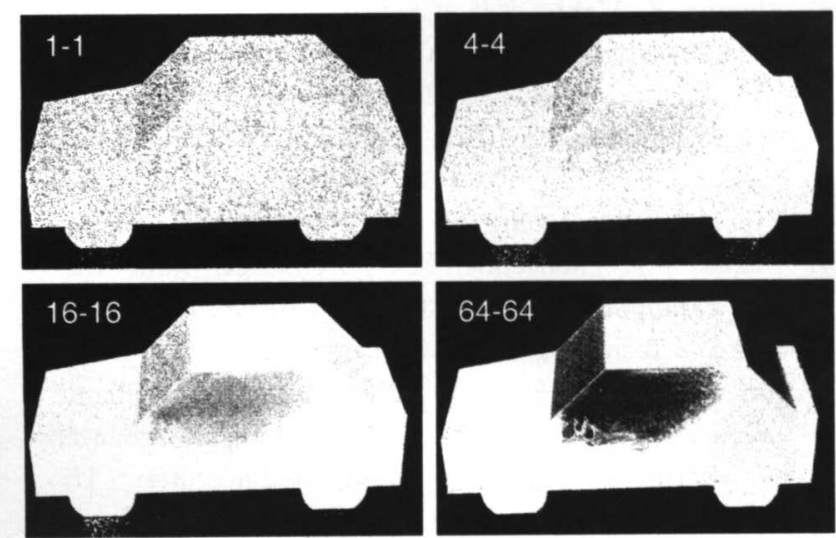

(c) $U=10 \mathrm{~m} / \mathrm{s}$

Fig. 5 Pressure distributions on the model at low speeds.
差である.

PSP によって得られた圧力分布と圧力孔データの比較 をFig. 6 に示す. 1-1 は各条件ともショットノイズ成 分が他のものと比較して大きいものの圧力孔データと一 番良く一致した. 平均画像枚数を増していくと前述の通 りショットノイズは低減するが, リアウインドウ部分 (part4)で圧力孔デー夕と大きくずれるようになった.こ の傾向は低速になるほど顕著になった。

この誤差要因を調べるために通風/無風画像の積算枚 数を変化させて得られた結果をFig. 7 に示す。これより 無風時画像を 4 枚平均した場合 $(1-4)$ よりも通風時
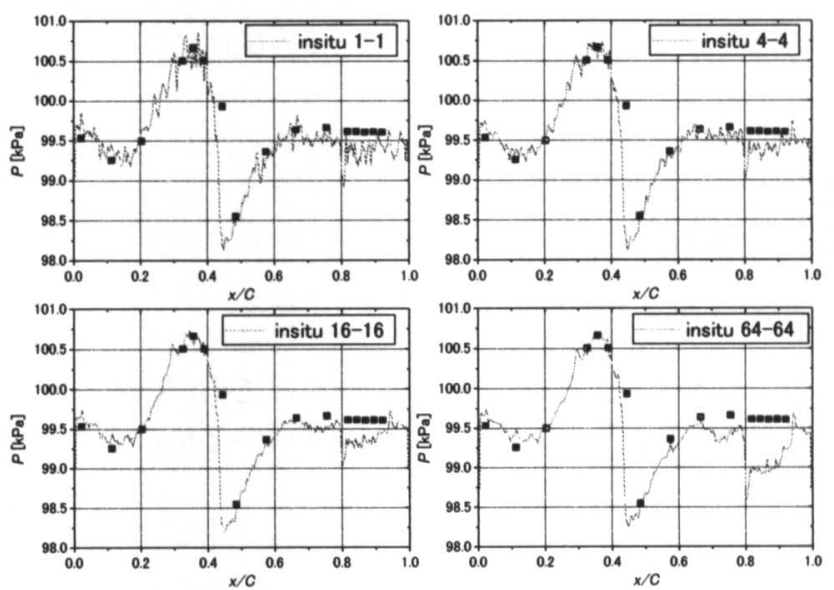

(a) $U=50 \mathrm{~m} / \mathrm{s}$
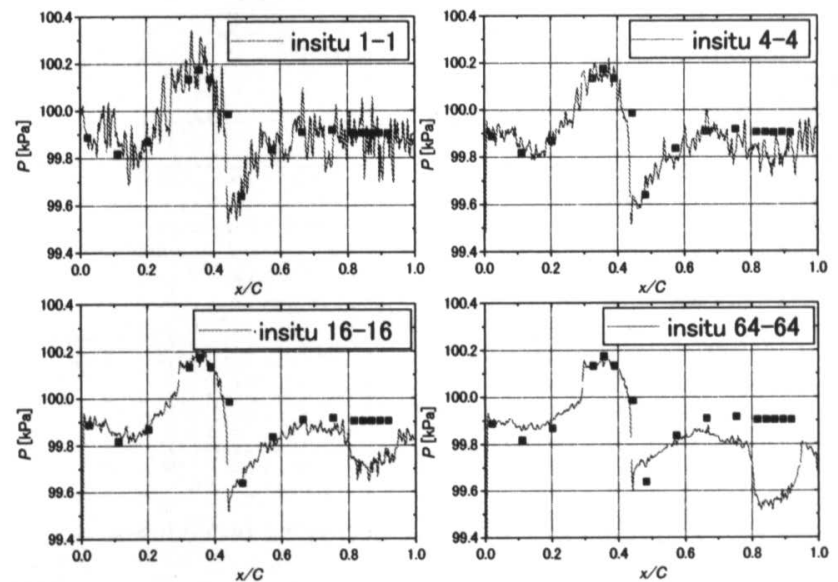

(b) $U=25 \mathrm{~m} / \mathrm{s}$
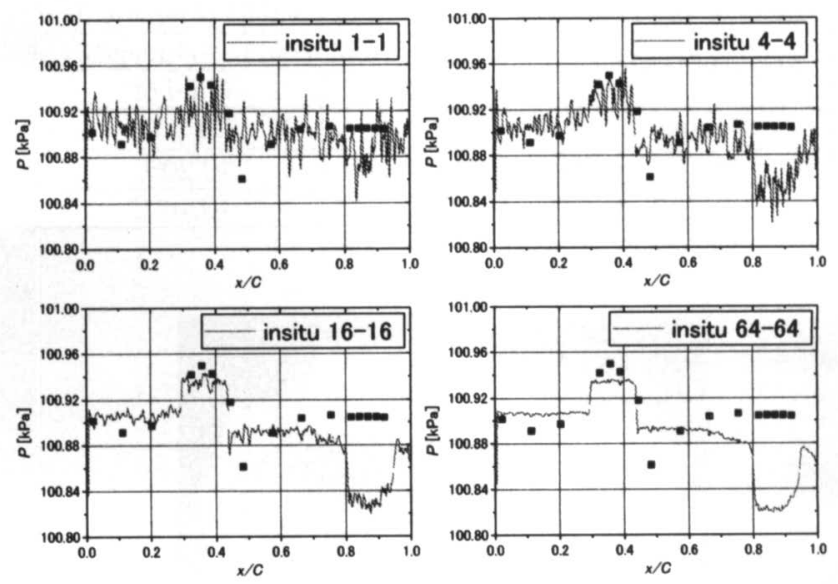

(c) $U=10 \mathrm{~m} / \mathrm{s}$

Fig. 6 Comparison between PSP data and pressure tap data. 
画像を 4 枚平均した場合 $(4-1)$ の方がより part4 の圧 力孔デー夕とのずれがより大きいことがわかる. Table 2 に示すように通風中の温度変化は無風時の温度変化より も大きかった。 ハッチバックの部分は剥離渦の中に位置 するため温度変化が他の部分と異なることが予想される． そのため画像の平均枚数を増やすことによって温度に由 来する誤差がこの部分でより大きくなったと考えられる。

Fig. 8 は通風前に無風画像を取得した場合の結果であ る. 通風/無風時で模型の温度差が大きく温度分布も異 なるため, 圧力デー夕は $1 \% /{ }^{\circ} \mathrm{C}$ あ温度誤差に埋もれて しまっている。このため模型温度分布ができる限り通風 時と等しくなるように無風時デー夕は通風後に取得する ことが必要であることがわかった。

今回用いた模型はアルミニウム製であったが, 例えば 熱伝導率が小さい材質（例えば木）の模型を用い, 主流 温度の変化に対し模型上の全ての点で同様に温度が変化 することで, 主流温度の変動の影響は補正できると考え られる。逆に模型を内部から強制的に均温化する方法も ある. 抜本的には, 模型の局所的な温度補正が行える複 合塗料や, 温度感度のより小さい PSP の開発が必要にな ると考えられる。
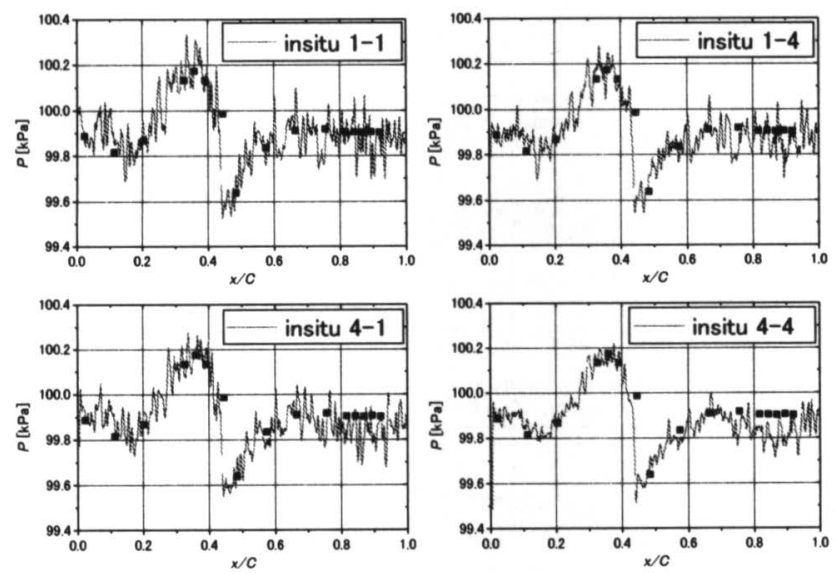

Fig. 7 Comparison of image averaging procedures.

Table 2 Temperature changes during the data acquisition.

\begin{tabular}{|c|c|c|}
\hline \multirow{2}{*}{ Mean Velocity } & \multicolumn{2}{|c|}{ Changes of temperature /64images } \\
\cline { 2 - 3 } & Wind on & Wind off \\
\hline $50 \mathrm{~m} / \mathrm{s}$ & $+3.8^{\circ} \mathrm{C}$ & $-1.2^{\circ} \mathrm{C}$ \\
\hline $25 \mathrm{~m} / \mathrm{s}$ & $+0.64^{\circ} \mathrm{C}$ & $-0.20^{\circ} \mathrm{C}$ \\
\hline $10 \mathrm{~m} / \mathrm{s}$ & $+0.13^{\circ} \mathrm{C}$ & $-0.10^{\circ} \mathrm{C}$ \\
\hline
\end{tabular}

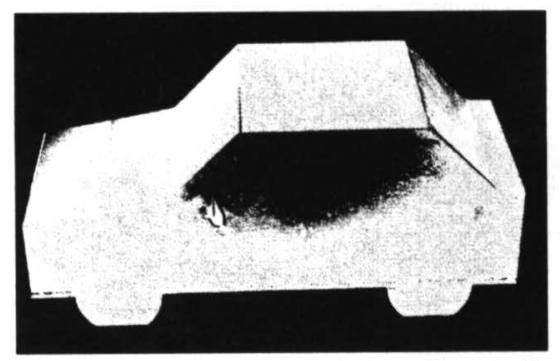

Fig. 8 Effects of selection of the reference image

\section{5. 結 言}

1）風速 $50 \mathrm{~m} / \mathrm{s}$ 以下の低速領域で自動車模型を用いた PSP 圧力計測を行った。その結果少なくとも風速 $25 \mathrm{~m} / \mathrm{s}$ 以上であれば in situ 較正を用いて定量的な圧 力分布が得られることがわかった。

2) 圧力の測定誤差要因でもっとも大きいものは温度誤 差であることがわかった.特に通風中の模型温度分布 の変化が大きな誤差を生み出すことがわかった。

3）温度由来する誤差を最小にするため通風時/無風時 間で模型の温度分布ができる限り等しくなるよう手 段を講じることが測定精度を向上する上で最も重要 である.無風時デー夕は上記の理由で通風直後に撮影 することが必要である.

4）今後,気流の温度変化の影響を抑え測定精度の向上を 図るには, 模型の材質を断熱性の高いものに変更する などの対策が有効であると考えられる，抜本的には， 局所的な温度補正が行える複合塗料や, 温度感度のよ ク小さいPSPの開発が必要である。

\section{謝 辞}

本研究の測定に際し, 航技研の中北和之氏, 西沢啓氏, 満尾和徳氏, 東京農工大の田部井孝聡氏の協力を得た. この場を借りて感謝の意を表す. 本研究の一部は, 文部 科学省科学技術振興調整費「機能性分子による熱流体七 ンシング技術の研究開発(MOSAIC)」により行われた。

\section{参考文献}

1) 浅井圭介, “感圧塗料技術の現状と展望,” 可視化情報学 会誌, Vol.21, No.83, 2001.10, pp. 203-208.

2) Bell, J. H., Schairer, E. T., Hand, L. A., et al: Surface Pressure Measurements Using Luminescent Coatings, Annu. Rev. Fluid Mech. Vol.33 (2001) pp.155-206.

3) Brown, O.C., Metha, B.J., and Cantwell, B.J.: Low-Speed Flow Studies Using the Pressure Sensitive Paint Technique, 81st AGARD/FDP, (1997).

4) Moris, M.J.: Use of Pressure Sensitive Paints in Low-Speed Flows, 16th ICIASF, USAF Wright Laboratory, $\mathrm{OH},(1995)$.

5) Shimbo, Y., Mehta, R.D., Cantwell., B.J.: Vortical Flow Field Investigation Using the Pressure Sensitive Paint Technique at Low Speed, AIAA 97-0388, (1997).

6) Torgenson, S.D., Tianshu, L. Sullivan, J.P.: Use of Pressure Sensitive Paint in Low Speed Flows, AIAA Paper 96-2184, (1996).

7) Engler, R.H., Mérienne, M.C., Klein, C., Sant, Y.L.: Application of PSP in Low Speed Flows, Aerospace Science and Technology Vol.6, (2002), pp.313-322.

8) Amao. Y., Asai, K, et al: Photophysical and Photochemical Properties of Optical Oxygen Pressure Sensor of Platinum Porphyrin-Isobutylmethacrylate- Trifluoroethylmethacrylate Copolymer Film, Polymer Journal, Vol.31, No.12, (1999), 1267-1296. 